\title{
Management of Alveolar Osteitis: A Comparative Study of Two-Treatment Techniques
}

\author{
Charles Ezechukwu Anyanechi
}

\section{ABSTRACT}

Background: The traditional method for the management of alveolar osteitis (dry socket) has its shortcomings in clinical dental practice as it takes long duration with frequent visits by the patients for completion of treatment. Objective is to determine the outcome of treatment using two techniques on patients who presented with alveolar osteitis following forceps dental extractions.

Materials and methods: This is a 3-year prospective study of 42 patients with alveolar osteitis seen at the University of Calabar Teaching Hospital, Nigeria. Following irrigation of the extraction sockets with dilute hydrogen peroxide, the sockets and surrounding gingival tissues were debrided to promote the reestablishment of the blood clot in the radical group, while in the traditional method, they were dressed with gauze impregnated with mixture of zinc oxide/eugenol.

Results: The age of patients ranged from 14 to 52 years, with the majority between 21 and 40 years $(n=27,64.2 \%)$. There were $24(57.1 \%)$ females and $18(42.9 \%)$ males with a male to female ratio of $1: 1.3$. More extraction sockets with alveolar osteitis were recorded in the mandible $(n=35,83.3 \%)$ than the maxilla ( $n=7,16.7 \%$ ); and in both jaws, the molar sockets (76.2\%) were predominant.

Conclusion: There is reduction in the duration of treatment in the radical group of patients when compared with those treated traditionally. This alternative treatment is safe and reliable and can be utilized by the practitioner who runs a busy clinic to save time. However, randomized controlled clinical trials are needed to validate this new technique.

Keywords: Forcep extraction, Alveolar osteitis, Radical approach, Mandible.

How to cite this article: Anyanechi CE. Management of Alveolar Osteitis: A Comparative Study of Two-Treatment Techniques. J Contemp Dent 2013;3(1):11-14.

Source of support: Nil

Conflict of interest: None declared

\section{INTRODUCTION}

The occurrence of alveolar osteitis (dry socket) following dentoalveolar surgeries is common. ${ }^{1-3}$ It occurs during the healing phase of extraction sockets, and some investigators ${ }^{4,5}$ regard it as the commonest postextraction complication. From the available literature, ${ }^{6-8}$ the traditional method for the treatment of this condition has its shortcomings in clinical dental practice as it takes long duration with frequent visits by the patients' for the completion of treatment. The therapeutic goal of the traditional method is based on the principle of relieve of patients' pain during the period of healing of the extraction socket.
Consequently, over the years, copious irrigation of the extraction socket with normal saline or dilute hydrogen peroxide and dressing with a medicament has become an established method in the treatment of postdental extraction sockets diagnosed as alveolar osteitis. This method of treatment has been found to be effective in the treatment of this painful condition. ${ }^{9,10}$ However, healing events within the postextraction sockets sometimes makes this treatment method to be prolonged with the patients having to attend dental surgery clinics severally for change of dressings before this disease process is completely eradicated. Although, the dressing is typically changed every 24 to 48 hours for 3 to 6 days, the exact frequency and duration is dictated by the patient's comfort requirements. ${ }^{11,12}$ Thus, the amount of working hours lost by the patients needing this palliative treatment, and the surgeon's productive time required, potentially translate to economic loss to the society. ${ }^{6}$ This would mean that a more economic method of treatment capable of reducing patients' morbidity and discomfort be developed. This study documents a new approach to the management of this condition and compared it with the traditional method.

\section{PATIENTS AND METHODS}

This is a prospective study of 42 patients who presented with alveolar osteitis following forceps dental extractions between January 2009 and December 2011 at the Dental and Maxillofacial Clinic of the University of Calabar Teaching Hospital, Calabar, Nigeria. This study was conducted in accordance with the Helsinki Declaration of 1975, as revised in 2000, and the Ethical Review Board of this institution approved the study. Included in the study were those patients' whose oral hygiene status were of good score using Gross plaque scoring method and antibiotics were not prescribed following the extraction. Those patients who reported to the clinic more than 7 days postoperatively were excluded. Also, 'patients with conditions such as diabetes mellitus, sickle cell disease, peptic ulcer, on steroid therapy, oral contraceptives and other local and systemic medical and surgical conditions adversely affecting wound healing or bone physiology and metabolism were excluded from the study.

The extractions of the teeth were done either under inferior alveolar nerve block or infiltration anesthesia. 
Moderate to severe dental pain, gingivitis around margins of the extraction sockets, exposure of the alveolar bone within the socket, coupled with partially or completely destroyed blood clot and necrotic food debris within the sockets, were the criteria for the diagnoses of alveolar osteitis. The patients were divided into two groups of A (control or traditional method, treated by dressing with gauze impregnated with zinc oxide/eugenol) and B (radical, treated by debridement). They were recruited into either group by simple random sampling as they presented with alveolar osteitis in the clinic. These extractions were performed by the author and one other dental surgeon, but the management of the alveolar osteitis was carried out by the author alone.

In only the radical group of patients, local anesthesia (2\% lignocaine with 1: 80,000 adrenalines) was administered to achieve analgesia at the site of the alveolar osteitis before commencement of treatment. In both the radical and control groups, the extraction sockets affected, with the surrounding gingival tissues were irrigated copiously with dilute hydrogen peroxide. For the control group, the extraction sockets were dressed with gauze impregnated with zinc oxide/eugenol, the size of the gauze being large enough to cover the circumference of the socket and partially tucked into it. In the radical group, debridement of the socket was carried out simultaneously with the irrigation, and this ensured bleeding. A piece of gauze pack was placed across the socket at the end of the procedure and the patients' asked to bite on it and swallow saliva. When hemostasis was achieved, the gauze pack was removed, and the routine instructions following dental extraction were given to the patients. Each patient in the radical group was also placed on antibiotics (amoxicillin, $500 \mathrm{mg} 8$ hourly for 5 days), antimicrobial (metronidazole, $200 \mathrm{mg} 8$ hourly for 5 days) and nonsteroidal anti-inflammatory analgesic (ibuprofen $400 \mathrm{mg} 8$ hourly for 3 days). Also, daily use of six tumblers of warm saline mouth wash spaced out at intervals of 2 hours and to start the next day was recommended for the patients in the two groups. The patients were discharged home, and six visits were scheduled for each subject with an interval of 2 days between visits. For the two groups of patients, the treatments were to be repeated when the symptoms persist during the follow-up reviews. The phone numbers of the patients were recorded in their case files for contact in case they fail to keep appointments. The variables documented in a proforma questionnaire for those with alveolar osteitis were age, gender, reasons for extraction, extraction sockets affected and number of treatment carried out in each patient to eradicate the disease. The data obtained were subjected to statistical analysis using EPI Info 2008 version software.

\section{RESULTS}

The total extraction sockets recorded in the patients was 3,101 , and 42 (1.35\%) of these sockets developed alveolar osteitis. The subjects that had extractions within the period was 2,012 with males ( $\mathrm{n}=1297,64.5 \%)$ and females ( $\mathrm{n}=715,35.5 \%$ ). The patients diagnosed with alveolar osteitis ( $n=42,2.1 \%)$ kept to the postextraction instructions and reported back to the clinic between 3 and 5 days after the dental procedure. Hence, the number of patients recruited into each of the two groups was 21.

Table 1 shows the distribution of the reasons for the dental extractions in the 42 subjects. Acute apical periodontitis and chronic irreversible pulpitis were predominant ( $n=29,69.1 \%$ ). Table 2 is on the distribution of age and gender of the subjects that developed alveolar osteitis. The age of patients ranged from 14 to 52 years with the majority ( $n=27,64.2 \%$ ) between 21 and 40 years, and mean $30 \pm 4.7$ years. The female gender was predominant in all the age categories except the 4th decade of life. There were 24 (57.1\%) females and 18 (42.9\%) males, giving male to female ratio of $1: 1.3$.

The distribution of the extraction sockets affected by alveolar osteitis is shown in Table 3 . The mandible accounted for more cases ( $\mathrm{n}=35,83.3 \%$ ) than the maxilla ( $\mathrm{n}=7,16.7 \%$ ). In both jaws, the cases involving the molar sockets ( $\mathrm{n}=32,76.2 \%$ ) were predominant, whereas no incisor socket was affected.

In the radical group of patients, only one surgical procedure was carried out to eradicate symptoms of the disease, whereas in the control (traditional) group, the distribution of patients in relation to number of treatments received is shown in Table 4 . Majority ( $n=20,95.2 \%)$ needed more than one procedure for successful treatment.

\section{DISCUSSION}

The dental extraction socket heals by secondary intention when the blood clot becomes organized as a result of the capillaries and fibroblasts that grow into it from the bony and soft tissue periphery. ${ }^{12,13}$ Alveolar osteitis causes delayed healing of the extraction socket and its etiology is not absolutely clear. Some researchers ${ }^{10,14}$ believe that it may be due to high levels of fibrinolytic activity within the

\begin{tabular}{lrc}
\hline \multicolumn{4}{c}{ Table 1: Reasons for dental extractions } \\
\hline Reason & No. & \multicolumn{1}{c}{$\%$} \\
\hline Acute apical periodontitis & 18 & 42.9 \\
Chronic irreversible pulpitis & 11 & 26.2 \\
Acute pulpitis & 9 & 21.4 \\
Chronic periodontitis & 4 & 9.5 \\
\hline Total & 42 & 100.0 \\
\hline
\end{tabular}


Management of Alveolar Osteitis: A Comparative Study of Two-Treatment Techniques

\begin{tabular}{|c|c|c|c|c|c|c|}
\hline \multirow[t]{2}{*}{ Age (years) } & \multicolumn{2}{|c|}{ Male } & \multicolumn{2}{|c|}{ Female } & \multicolumn{2}{|c|}{ Total } \\
\hline & No. & $\%$ & No. & $\%$ & No. & $\%$ \\
\hline $11-20$ & 2 & 4.8 & 4 & 9.5 & 6 & 14.3 \\
\hline $21-30$ & 5 & 11.9 & 8 & 19.0 & 13 & 30.9 \\
\hline $31-40$ & 8 & 19.0 & 6 & 14.3 & 14 & 33.3 \\
\hline $41-50$ & 2 & 4.8 & 4 & 9.5 & 6 & 14.3 \\
\hline $51-60$ & 1 & 2.4 & 2 & 4.8 & 3 & 7.2 \\
\hline Total & 18 & 42.9 & 24 & 57.1 & 42 & 100.0 \\
\hline
\end{tabular}

extraction socket. This fibrinolytic event results in lysis of the blood clot and subsequent exposure of the bone. However, the fibrinolytic process may be the consequence of subclinical infection, inflammation of the marrow spaces of the bone or some other factors. ${ }^{13,14}$ Supporting this view are several studies ${ }^{15,16}$ in the past which have confirmed the oral environment as polymicrobial with anaerobes outnumbering aerobes in the ratio of 2:1. It was also reported that this condition, if left untreated, may progress to osteomyelitis or to a severe cellulitis of the face and neck. ${ }^{13,14}$

The methods used to manage the patients in this series provided aerobic condition within the extraction sockets due to the hydrogen peroxide being an oxidizing agent. The re-establishment of blood clot and the protection of this clot by the use of amoxicillin, metronidazole and ibuprofen in the radical group enhanced uneventful healing process. This resulted in the reduction of the duration of treatment, patient discomfort and morbidity. Some authors have also promoted

Table 3: Distribution of alveolar osteitis according to site

\begin{tabular}{lrr}
\hline Site & No. & $\%$ \\
\hline Mandible & & \\
Molar & 28 & 66.7 \\
Premolar & 4 & 9.5 \\
Canine & 3 & 7.1 \\
\hline Total & 35 & 83.3 \\
\hline Maxilla & & \\
Molar & 4 & 9.5 \\
Premolar & 2 & 4.8 \\
Canine & 1 & 2.4 \\
\hline Total & 7 & 16.7 \\
\hline
\end{tabular}

Table 4: Distribution of patients in relation to treatment
received (traditional method)

the use of eugenol containing dressing for the treatment and prevention of alveolar osteitis. ${ }^{6,17}$ However, irritant local effect of eugenol and the delay in wound healing due to packing of the socket has been documented in the literature. ${ }^{18}$ Other topical products that have been reported and are of beneficial effect in the treatment and prevention of alveolar osteitis include $0.12 \%$ chlorhexidine gluconate, betadine mouthwash, benzocaine, topical antimicrobials (iodoform), platelet-rich plasma, topical antibiotics such as tetracycline, clindamycin or a combination of bacitracin, neomycin and tetracycline. ${ }^{8-10,19}$

The management of alveolar osteitis is less controversial than its etiology and prevention. ${ }^{18}$ In the traditional method of treatment, the primary aim of dry socket management, as indicated by Fazakerley, ${ }^{20}$ is pain control until commencement of normal healing, and in the majority of cases these measures are satisfactory. In some instances, systemic analgesics or antibiotics may be necessary or indicated, and this explains the reason for the exclusion criteria in the present study. The use of intra-alveolar dressing materials is widely suggested in the literature, although it is generally acknowledged that dressings delay healing of the extraction socket. ${ }^{21}$ Different medicaments and carrier systems are commercially available with little scientific evidence to guide a selection process. ${ }^{18}$ As the various formulations are reviewed, it becomes apparent that all of them are simply varying combinations of perhaps 18 different ingredients. ${ }^{18,22}$ Thus, this new approach to treatment documented in the present study is recommended as it obviate these shortcomings and shorten the duration of treatment and consequently, the period of recovery and healing.

The onset of alveolar osteitis is considered to occur 1 to 3 days after tooth extraction, and 95 to $100 \%$ of all cases have been reported within a week. ${ }^{23-25}$ The patients in the present study reported 3 to 5 days postoperatively. The $2.1 \%$ of the subjects and $1.35 \%$ of the extraction sockets that developed alveolar osteitis are similar to the results of previous researchers ${ }^{11,13}$ but differ from the study in Lagos by Adeyemo et $\mathrm{al}^{2}$ although their reports were based on impacted mandibular third molar teeth unlike the present study. The reasons for extractions are consistent with earlier 
reports. $^{2,12}$ The peak and mean ages are as reported earlier ${ }^{5,8}$ while the gender predilection is in conformity with the report of other investigators. ${ }^{3,4}$ However, Colby ${ }^{26}$ reported no difference in the incidence of alveolar osteitis associated with gender.

Alveolar osteitis occurred more in the mandible than the maxilla. This is due to the better vascularization of the maxilla than mandible. ${ }^{13,14}$ Also, the more cases recorded in the molar sockets is due to the wider circumference of its socket and the resultant blood clot compared with the others, which probably exposed the blood clot to more fibrinolytic activity.

\section{CONCLUSION}

These two approaches to the treatment of alveolar osteitis have demonstrated reliability and predictability. However, there is reduction in the duration of treatment and consequently, discomfort and morbidity in the radical group of patients when compared with those treated traditionally. This alternative treatment is safe and reliable and can be utilized by the practitioner who runs a busy clinic to save time. However, randomized controlled clinical trials are needed to validate this new technique.

\section{REFERENCES}

1. Blondeau F, Daniel NG. Extraction of impacted mandibular third molars: Postoperative complications and their risk factors. J Can Dent Assoc 2007;73:325-30.

2. Adeyemo WL, Ladeinde AL, Ogunlewe MO. Influence of transoperative complications on socket healing following dental extractions. J Contemp Dent Pract 2007;8:52-59.

3. Bouloux GF, Steed MB, Perciaccante VJ. Complications of third molar surgery. Oral Maxillofac Surg Clin North Am 2007;19: 117-28.

4. Blum IR. Contemporary views on dry socket (alveolar osteitis): A clinical appraisal of standardization, aetiopathogenesis and management: A critical review. Int J Oral Maxillofac Surg 2002;31:309-17.

5. Jaffar RO, Tin-Oo MM. Impacted mandibular third molars among patients attending Hospital Universiti Sains Malaysia: Arch Orofac Sci 2009;4:7-12.

6. Vezeau PJ. Dental extraction wound management: Medicating post-extraction sockets. J Oral Maxillofac Surg 2000;58: 531-37.

7. Alissa R, Esposito M, Horner K, Oliver R: The influence of platelet-rich plasma on the healing of extraction sockets: An explorative randomized clinical trial. Eu J Oral Implantol 2010;3: 121-34.

8. Noroozi AR, Philbert RF. Modern concepts in understanding and management of the dry socket syndrome: Comprehensive review of the literature. Oral Surg Oral Med Oral Pathol Oral Radiol Endod 2009;107:30-35.
9. Rutkowski JL, Fennell JW, Kern JC, Madison DE, Johnson DA: Inhibition of alveolar osteitis in mandibular teeth extraction sites using platelet-rich plasma. J Oral Implantol 2007;33:116-21.

10. Swanson AE. A double-blind study on the effectiveness of tetracycline in reducing the incidence of fibrinolytic alveolitis. J Oral Maxillofac Surg 1989;47:165-67.

11. Chiapaso M, Decicco L, Marrone G. Side effects and complications associated with third molar surgery. Oral Surg Oral Med Oral Pathol 1993;76:412-20.

12. Chukwuneke FN. A comparative study of the effect of different third molar impactions on postoperative morbidity following lower third molar surgery. J Coll Med, University of Nigeria Nsukka 2006;11:82-87.

13. Moore JR. Principles of oral surgery. Manchester: Manchester University Press 1976;128.

14. Peterson LJ. Postoperative patient management. In Peterson LJ, Ellis 111 E, Hupp JR, Tucker MR (Eds). Contemporary oral and maxillofacial surgery. ST Louis: Mosby 1993;261-88.

15. Moore WEC, Ranney RR, Holdeman LV. Subgingival microflora in periodontal disease. Am Soc Microbiol 1982;13:26-30s.

16. Moenning JE, Nelson CL, Kohler RB. The microbiology and chemotherapy of odontogenic infections. J Oral Maxillofac Surg 1989;47:976-85.

17. Torres-Lagares D, Serrera-Figallo MA, Romero-Ruíz MM, Infante-Cossío P, García-Calderón M, Gutiérrez-Pérez JL. Update on dry socket: A review of the literature. Medicina Oral, Patologia Oral y Cirugia Bucal 2005;10:77-85.

18. Kolokythas A, Olech E, Miloro M. Alveolar osteitis: A comprehensive review of concepts and controversies. Int J Dent 2010;249073.

19. Caso A, Hung LK, Beime OR. Prevention of alveolar osteitis with chlorhexidine: A meta-analytic review. Oral Surg Oral Med Oral Pathol Oral Radiol Endod 2005;99:155-59.

20. Fazakerley M, Field EA. Dry socket: A painful post-extraction complication (a review). Dental Update 1991;18:31-34.

21. Schatz JP, Fiore-Donno G, Henning G. Fibrinolytic alveolitis and its prevention. Int J Oral and Maxillofac Surg 1987;16:175-83.

22. Alexander RE. Dental extraction wound management: A case against medicating post-extraction sockets. J Oral Maxillofac Surg 2000;58:538-51.

23. Field EA, Speechley JA, Rotter E, Scott J. Dry socket incidence compared after a 12 year interval. British J Oral Maxillofac Surg 1985;23:419-27.

24. Fridrich KL, Olson RAJ. Alveolar osteitis following surgical removal of mandibular third molars. Anesth Progr 1990;37: 32-41.

25. Rood JP, Murgatroyd J. Metronidazole in the prevention of dry socket. British J Oral Surgery 1979;17:62-70.

26. Colby RC. The general practitioner's perspective of the etiology, prevention, and treatment of dry socket. Gen Dent 1997;45: $461-72$.

\section{ABOUT THE AUTHOR}

\section{Charles Ezechukwu Anyanechi}

Lecturer, Consultant, Department of Dental Surgery, University of Calabar, Cross River, Nigeria, e-mail: ceanyanechi@yahoo.com 